\title{
A Calibrating Six-Port Compact Circuit using a New Technique Program
}

\author{
Traii Moubarek ${ }^{1,2}$, Mohannad Almanee ${ }^{2}$, Ali Gharsallah ${ }^{3}$ \\ Dept. of physics, Lab CSEHF, Faculty of sciences of Tunis, El-manar, Tunisia, 3 \\ Dept. of electronics, Riyadh College of Technology, tvtc, Saudi Arabia ${ }^{1,2}$
}

\begin{abstract}
In this paper, a calibration of six-port reflectometer using a new technique program is presented. It has been shown that a calibration procedure is based on explicit method, the method that capturing the output wave forms of sixport junction and determines the complex relationship between the two waves present at the input from the value of four outputs. The number of calibrating standards and the computation effort required are the most important parameters in selecting a calibration technique. Comparison between the results obtained from the new calibration method program with measurement results show the validity of the method proposed. This calibration technique can be used in general six-port direct digital receiver.
\end{abstract}

Keywords-Calibration technique; digital receiver; explicit method; reflectometer; $S$ parameters

\section{INTRODUCTION}

Recently, six-port concept has been successfully applied in modern communication receivers. For this reason, calibration procedure is very important for the measurement accuracy. Many microwave applications require the determination of the reflection and or the transmission properties of a device undertest (DUT) over a specified frequency band. Various calibration procedures for six-port junction have been suggested along the years [1-2]. Among the many programs which have been proposed for the calibration of six-port reflectometer, Hassan [3], introduced, the accuracy calibration of a six-port reflectometer as an alternative to the conventional ANA.

On the other hand, Yanyang and Frigon presented a new type of six-port radio for ultra wideband containing one power detector and one variable reference load [4]. Yanyang pointed out that there exist exact relations between some system parameters and integral quantities of the detected values for a number of reference plane positions [5]. This technique is advantageous for permitting automatic procedures; nevertheless it requires a great amount of time to be accomplished and demands a large number of known standards necessary to the network training. Another technique requires Schottky diodes with homodyne detection, but this procedure would be entirely impractical to analyze a calibration procedure [6].

Eventually, in this paper, a novel calibration method for a compact six-port junction in SHF band is presented, in which a remarkable improvement is achieved. The main objective is to minimize the number of known standards required to increase the dynamic range of the six-port reflectometer and accuracy of the measurements. Following this, the simplicity of the method provides for automatic calibration of modern applications like wireless receivers. The comparison between theoretical results and those obtained from graphic interface and experimental results is presented to demonstrate the validity of the system developed.

The analysis of the SPR, which is based on an analytical description of the system behavior, is given in Section II. In Section III-A, six-port calibration techniques have been widely described. Finally the comparison between practical results, developed program and those obtained by commercial software is presented in Section III-B to demonstrate the validity of the system developed.

\section{SYSTEM DESIGN}

The six-port reflectometer provides an alternative method of implementing the ANA [7]. In common with the existing design, CST Microwave Studio is chosen due to its ability for the simulation and analysis of these items.

\section{A. The Proposed Six-Port Circuit}

The layout and prototype of six-port junction used in calibrating system is shown in Fig. 1, experimental results have been performed by using a HP8722 network analyzer.

It was designed with RT/Duroid 6010LM having a thickness $\mathrm{h}=0.508 \mathrm{~mm}$ and a relative dielectric constant $\varepsilon \mathrm{r}=$ 3.38 .

The configuration of a compact six-port junction is designed using elliptic-disc coupler with delay line us shown in Fig. 1(a). by suitable choice of larger spacing between line delay of compact elliptic coupler [8], a flat-coupling response is obtained for the coupled ports, Table I shows the dimension of miniaturized six-port prototype.

TABLE I. PARAMETERS OF THE PROPOSED SIX-PORT

\begin{tabular}{|l|l|l|l|}
\hline \multirow{2}{*}{ Parameter values } & \multicolumn{2}{|l|}{ Values, mm } \\
\cline { 2 - 4 } & $\begin{array}{l}\text { Initial } \\
\text { values }\end{array}$ & $\begin{array}{l}\text { Optimum } \\
\text { values }\end{array}$ & $\begin{array}{l}\text { values } \text { in } \\
\text { [8] }\end{array}$ \\
\hline Semi-major (Sm) elliptical axis & 21.5 & 21.44 & 25.71 \\
\hline$W$ (width of the impedance steps) & 2.25 & 2.23 & 2.31 \\
\hline Ds (length of the impedance) & 4.95 & 4.91 & 5.2 \\
\hline $\begin{array}{l}\text { Slot s (widh of delay line in } \\
\text { compact elliptic coupler) }\end{array}$ & 1.8 & 1.85 & - \\
\hline D (dimension of six-port junction) & 73.1 & 72.82 & 87.14 \\
\hline
\end{tabular}


As can be seen from Fig. 1(b), ports 1 and 2 are connected to a local oscillator and received RF signals, respectively. The other four ports (ports 3-6) are output ports and are connected to power detectors.

Fig. 2 compares the simulated and measured scattering parameters of fabricated single layer six-port prototype.

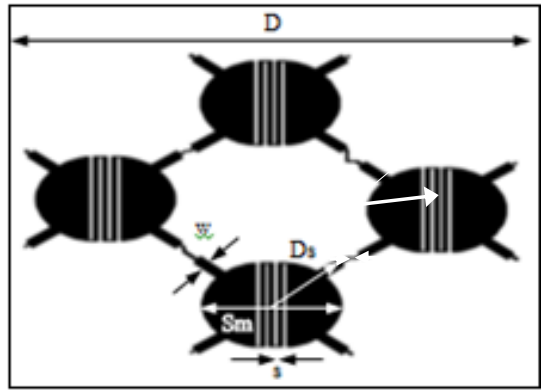

(a)

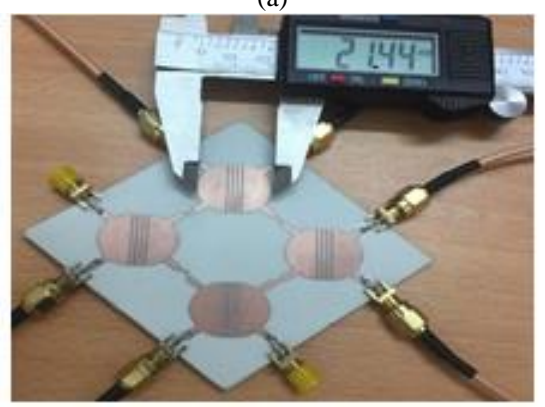

(b)

Fig. 1. Photograph of the Proposed Six-Port Prototype, (a) Layout Design, (b) Fabricated Prototype.

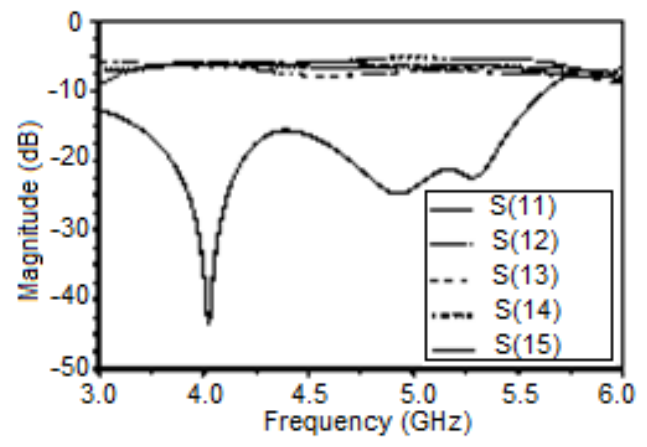

(a)

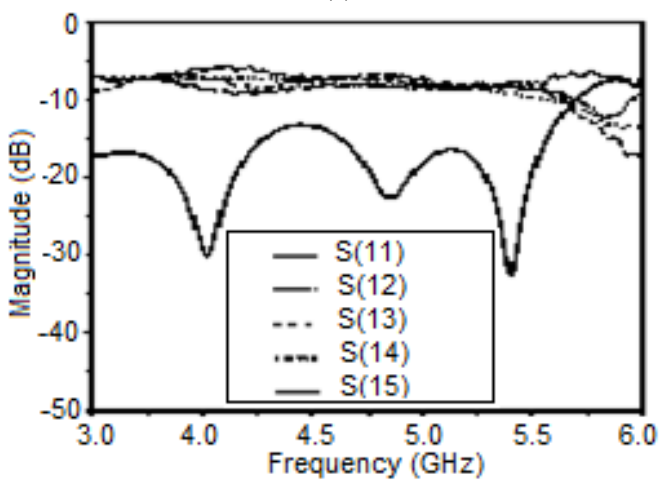

(b)

Fig. 2. Scattering Parameters of Single Layer Six-Port, (a) Simulation Results, Measured Results.
To reconfigure the magnitude a characteristic, the six-port junction is adapted from 3 to $6 \mathrm{GHz}$ with a resonance frequency around $4.5 \mathrm{GHz}$. This figure shows that the measured transmission coefficients of the proposed six-port circuit has some ripples in measurement results compared to the simulated ones, which may be caused by the SMA feed connector. It can be noted that the return loss is better than 15 $\mathrm{dB}$ over the entire operating frequency band of interest.

The proposed six-port prototype has the advantages of small volume and low cost compared to published design [8].

\section{B. Reflectometer System with Proposed Six-Port}

The system generates a signal $\rho(n)$ in the digital domain representing the complex ratio between the two input signals of six-port junction above.

Four diode power detectors $\left(\mathrm{D}_{3}, \mathrm{D}_{4}, \mathrm{D}_{5}\right.$, and D6) enable the use of ac detection. The power detectors connected at output ports 3, 4, 5 and 6 respectively comprise silicon Schottky diodes (Hughes 47436H-11) and RC low-pass filter.

Fig. 3 shows the measurement of the output power levels from six-port junction; also convert the $\mathrm{AC}$ voltage with high frequency to DC voltage with low frequency which is then passed to the calibration routine. The voltage values measured at the power detectors outputs are given by the following equation [9]:

$V_{i}(t)=a_{i} \cdot V_{L O}^{2}+b_{i} \cdot V_{R F}^{2}(t)+c_{i} \cdot V_{R F}(t) \cdot \cos \left(\theta(t)-\emptyset_{i}\right)$

Where:

$-\quad \mathrm{i}=3, \ldots 6$

- $\emptyset_{\mathrm{i}}=\varphi_{\mathrm{i}}-\gamma_{\mathrm{i}}$,

- $\quad \mathrm{c}_{\mathrm{i}}$ : Depends on $\mathrm{a}_{\mathrm{i}}, \mathrm{b}_{\mathrm{i}}$ and $\mathrm{V}_{\mathrm{LO}}$ which is supposed to be Constant.

The use of four Schottky diode detectors presents a costeffective solution and offers a good alternative for applications where speed is important, they present linear characteristics at low power levels and high power levels respectively [10].

Four analog-to-digital converters (A $/ \mathrm{D})$ and a digital signal processor (DSP) connected to pc analyser.

Input signal $v_{r f}(t)$ and $v_{L O}(t)$ with various phases as below:

$\mathrm{v}_{\mathrm{LO}}(\mathrm{t})=\mathrm{V}_{\mathrm{LO}} \cos (\mathrm{wt})$

$\mathrm{V}_{\mathrm{rf}}(\mathrm{t})=\operatorname{Re}\left[\mathrm{V}_{\mathrm{RF}}(\mathrm{t}) \mathrm{e}^{\mathrm{j}(\mathrm{wt}+\theta(\mathrm{t}))}\right]$

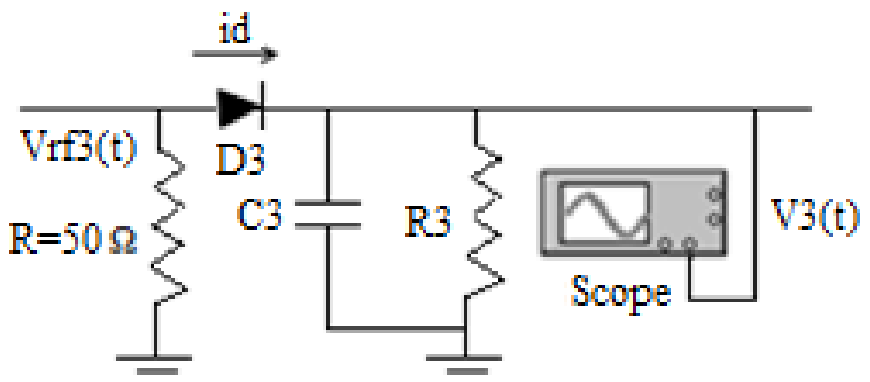

Fig. 3. Power Detector at Port 3 (i=3). 
Let us consider the cases where the incident and reflected signals $\mathbf{a}$ and $\mathbf{b}$ respectively has different frequencies, as in the following:

$\mathrm{a}=|\mathrm{a}| \cdot \mathrm{e}^{\mathrm{j}\left(2 \Pi \mathrm{f}_{1} \mathrm{t}+\phi_{1}\right)}$

$\mathrm{b}=|\mathrm{b}| \cdot \mathrm{e}^{\mathrm{j}\left(2 \Pi \mathrm{f}_{2} \mathrm{t}+\phi_{2}\right)}$

As illustrated in Fig. 4, the block diagram of six-port reflectometer with power detector, the manufacturer part labels provided in the figure correspond to those components used to implement the method in this work. The out coming RF signals at the reflectometer ports $3,4,5$ and 6 have the form:

$\mathrm{V}_{\mathrm{rfi}}(\mathrm{t})=\sqrt{\mathrm{a}_{\mathrm{i}}} \cdot \mathrm{V}_{\mathrm{LO}} \cdot \cos \left(\mathrm{wt}+\emptyset_{\mathrm{i}}\right)+\sqrt{\mathrm{b}_{\mathrm{i}}} \cdot \mathrm{V}_{\mathrm{RF}}(\mathrm{t}) \cdot \cos (\mathrm{wt}+$ $\left.\theta(\mathrm{t})+\theta_{\mathrm{i}}\right)$

Where:

- $\mathrm{i}=3, \ldots, 6$,

- $\varphi_{i}$ is the phase of $\mathrm{v}_{\mathrm{LO}}(\mathrm{t})$ at port $\mathrm{i}$ with respect to port 1 ,

- $\gamma_{\mathrm{i}}$ is the phase of $v_{r f}(t)$ at port i relative to port 2 ,

- $a_{i}, b_{i}$ depend on the circuit characteristics.

The term $\mathrm{V}_{\mathrm{RF}}(\mathrm{t}) \cos \left(\theta(\mathrm{t})-\emptyset_{\mathrm{i}}\right)$ is a projection of $v_{r f}(t)$. After a trigonometric calculation, (6) becomes:

$$
\begin{aligned}
\hat{U}_{i}(t) & =b_{i} V_{R F}^{2}(t)+c_{i} \cos \emptyset_{i} U(t)+c_{i} \sin \emptyset_{i} V(t) \\
\hat{U}_{i}(t) & =v_{i}(t)-a_{i} V_{L O}^{2} ; i=3, . ., 6 \\
U(t) & =V_{R F}(t) \cos \theta(t) \\
V(t) & =V_{R F}(t) \cdot \sin \theta(t)
\end{aligned}
$$

Calibration method of the six-port system is based in previous calculation; this calibrating program consists in finding a signal $\rho(n)$ in the complex domain.

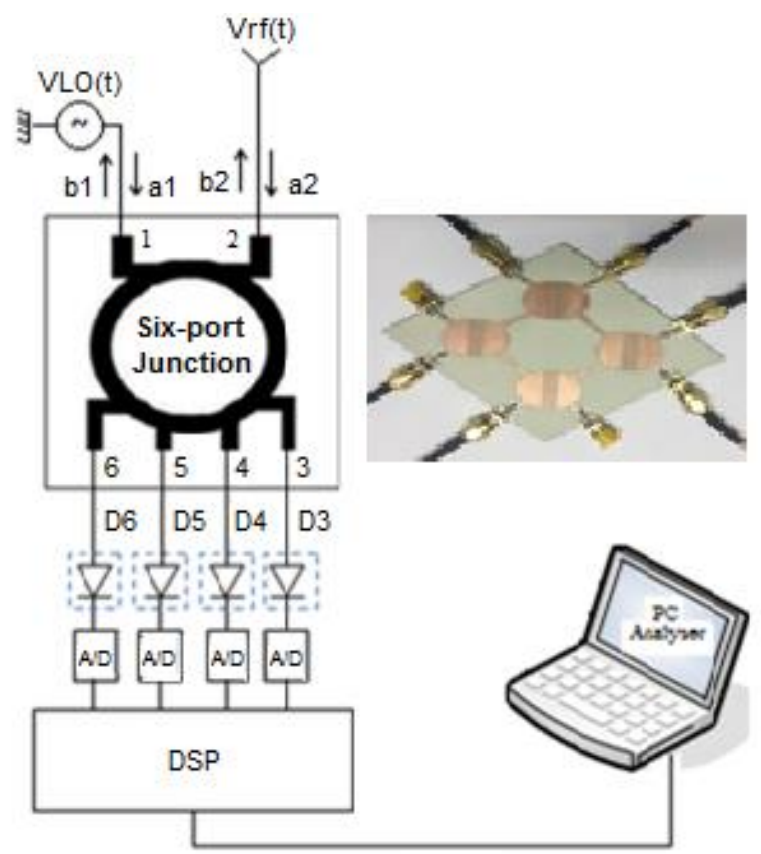

Fig. 4. Block Diagram of Six-Port Reflectometer with Power Detector.

\section{Calibrating Technique Proposed}

Six-port calibration techniques have been widely reported in the literature [11], [12]. All of the methodologies that begin with the relation between the power measurements and the reflection coefficient are suited only for an intrinsically narrow-band system.

To over this drawback, we study in this paper the six-port reflectometer with power detectors, a measurement port and four sidearm ports to which power detectors are connected. It measures the reflection coefficient of a device under test (DUT) in terms of magnitude and phase using four sidearm power readings and eleven system parameters composed of three real quantities and four complex quantities [13].

Thus, the key problem in the practical use of the six-port reflectometer is how to determine the eleven frequency dependent system parameters, with fewer calibration standards and with less computational effort. For digital processing of out coming six-port reflectometer, it is essential to find a mathematical modeling of output quantities.

Below the model used to express the detected voltages $V_{1}$ to $V_{4}$ depending on the module $|\Gamma|$ and phase $\Phi$ of the reflection coefficient $S_{11}$ of the DUT [14]:

$\mathrm{V}_{\mathrm{i}}=\mathrm{a}_{\mathrm{i} 0}+\mathrm{a}_{\mathrm{i} 1} \cdot|\Gamma|^{2}+\mathrm{a}_{\mathrm{i} 2} \cdot|\Gamma| \cdot \sin (\varnothing)+\mathrm{a}_{\mathrm{i} 3} \cdot|\Gamma| \cdot \cos (\varnothing)+$

$\mathrm{a}_{\mathrm{i} 4 \cdot} \cdot|\Gamma|^{2} \cdot \sin (2 \varnothing)+\mathrm{a}_{\mathrm{i} 5} \cdot|\Gamma|^{2} \cdot \cos (2 \varnothing)$

$\mathrm{i}=1 \ldots 6$

By using the real and imaginary parts of $\Gamma$, it is possible to rephrase the previous model by:

$V_{i}=b_{i 0}+b_{i 1} \cdot I+b_{i 2} \cdot Q+b_{i 3} \cdot I^{2}+b_{i 4} \cdot Q^{2}+b_{i 5} \cdot I \cdot Q+$

$\cdots+b_{\text {in }}$

Where:

$\mathrm{I}=\operatorname{Re}(\Gamma), \mathrm{Q}=\operatorname{Im}(\Gamma)$

$b_{i j}$ : Calibration constant.

$n$ : Index number of minimum standards.

We present below three different levels retainer model:

$\mathrm{V}_{\mathrm{i}}=\mathrm{b}_{\mathrm{i} 0}+\mathrm{b}_{\mathrm{i} 1}+\mathrm{b}_{\mathrm{i} 2} \mathrm{Q}+\mathrm{b}_{\mathrm{i} 3}\left(\mathrm{I}^{2}+\mathrm{Q}^{2}\right)$

$\Rightarrow$ First order for $i=1, \ldots, 4$

$\mathrm{V}_{\mathrm{i}}=\mathrm{b}_{\mathrm{i} 0}+\mathrm{b}_{\mathrm{i} 1} \mathrm{I}+\mathrm{b}_{\mathrm{i} 2} \mathrm{Q}+\mathrm{b}_{\mathrm{i} 3} \mathrm{I}^{2}+\mathrm{b}_{\mathrm{i} 4} \mathrm{Q}^{2}+\mathrm{b}_{\mathrm{i} 5} \mathrm{IQ}$

$\Rightarrow$ Second order for $i=1, \ldots, 4$

$\mathrm{V}_{\mathrm{i}}=\mathrm{b}_{\mathrm{i} 0}+\mathrm{b}_{\mathrm{i} 1} \cdot \mathrm{I}+\mathrm{b}_{\mathrm{i} 2} \cdot \mathrm{Q}+\mathrm{b}_{\mathrm{i} 3} \cdot \mathrm{I}^{2}+\mathrm{b}_{\mathrm{i} 4} \cdot \mathrm{Q}^{2}+\mathrm{b}_{\mathrm{i} 5} \cdot \mathrm{IQ}+$

$b_{i 6} \cdot\left(I^{2}-3 I Q^{2}\right)+b_{i 7} \cdot\left(Q^{2}-3 I^{2} Q\right)$

$\Rightarrow$ Third order for $i=1, \ldots, 4$

The $b_{i j}$ terms representing calibration constants depending only on the terms $a_{i j}$. The advantage of using such a development (13), (14) and (15) is to assign the same variation ranges to two quantities of interest $(I \in[-1,1]$ and $Q \in$ $[-1,1])$ that we are trying to determine. Indeed, given the form of expressions, it appears that resolution requires the implementation of a digital resolution in two dimensions. 
These equations are used to express the magnitudes of interest (I and Q) as a function of the measured voltages on each of the detectors $\left(\mathrm{V}_{3}, . ., \mathrm{V}_{6}\right)$ [15]. I and $\mathrm{Q}$ are related by the reflectometer calibration constants.

This calibration consists in solving the equations of the model by considering the known loads and measuring the tensions of these standard loads. Inputs correspond to a matrix of the measured voltages $\mathrm{V}_{\mathrm{M}}$ while the resulting matrix contains the terms $\mathrm{I}$ and $\mathrm{Q}$. The calibration constants are grouped in two known matrices $\mathrm{B}_{0}$ and $\mathrm{B}_{\mathrm{M}}$.

Note that the parameters that depend on the order of the model are: The number of standard loads required for calibration \{(4 loads: order 1); (6 loads: order 2$)$; (8 loads: order 3$)\}$. The dimension of the calibration matrix $\{(3 \times 4$, order $1) ;(5 \times 4$, order 2$) ;(7 \times 4$, order 3$)\}$. In order to optimize the accuracy/ computation time, we reduce the number of used standard and minimize the number of test, we will adopt the second model. i denotes the ith outputs.

$V_{i}=b_{i 0}+b_{i 1} \cdot I+b_{i 2} \cdot Q+b_{i 3} \cdot I^{2}+b_{i 4} \cdot Q^{2}+b_{i 5} \cdot I Q$

For a load with reflection coefficient $\Gamma$, the four equations form a linear system of five variables. The type (I, $\left.Q, I^{2}, Q^{2}, I Q\right)$ with:

$\mathrm{V}_{\mathrm{M}}=\mathrm{B}_{\mathrm{M}} \cdot \Gamma_{\mathrm{M}}+\mathrm{B}_{0}$

$\mathrm{V}_{\mathrm{M}}=\left[\begin{array}{l}\mathrm{V}_{1} \\ \mathrm{~V}_{2} \\ \mathrm{~V}_{3} \\ \mathrm{~V}_{4}\end{array}\right]$

$B_{M}=\left[\begin{array}{lllll}b_{11} & b_{12} & b_{13} & b_{14} & b_{15} \\ b_{21} & b_{22} & b_{23} & b_{24} & b_{25} \\ b_{31} & b_{32} & b_{33} & b_{34} & b_{35} \\ b_{41} & b_{42} & b_{43} & b_{44} & b_{45}\end{array}\right]$

$\Gamma_{\mathrm{M}}=\left[\begin{array}{c}\mathrm{I} \\ \mathrm{Q} \\ \mathrm{I}^{2} \\ \mathrm{Q}^{2} \\ \mathrm{I} . \mathrm{Q}\end{array}\right]$

$B_{0}=\left[\begin{array}{l}b_{11} \\ b_{21} \\ b_{31} \\ b_{41}\end{array}\right]$

$V_{M}$ : Matrix of the detected voltages;

$\Gamma_{M}$ : Matrix containing the appropriate quantities I and Q;

$B_{M}$ : Matrix of the calibration coefficients of the I and Q magnitudes;

$B_{0}$ : Matrix of the DC components of the voltages $V_{i}$,

$\mathrm{i}=1, \ldots, 4$.

Knowledge of $\mathrm{B}_{\mathrm{M}}$ matrices, $\mathrm{B}_{0}$ is associated with the measurement of the four voltages $V_{1}$ to $V_{4}$ allows then the determination of $\mathrm{I}$ and $\mathrm{Q}$ by reversing the previous matrix system:
$\Gamma_{\mathrm{M}}=\mathrm{B}_{\mathrm{M}}^{-1}\left(\mathrm{~V}_{\mathrm{M}}-\mathrm{B}_{0}\right)$

The solution of the above matrix equation leads to the calculation of $\mathrm{B}_{\mathrm{M}}$ and $\mathrm{B}_{0}$ corresponds to the calibration of the six-port junction.

\section{A. Algorithm and Interface}

The algorithm is based on the mathematical development of explicit calibration above. The inputs in this program are determined in the previous paragraph. We can summarize the different steps in the calculation by the following chart:

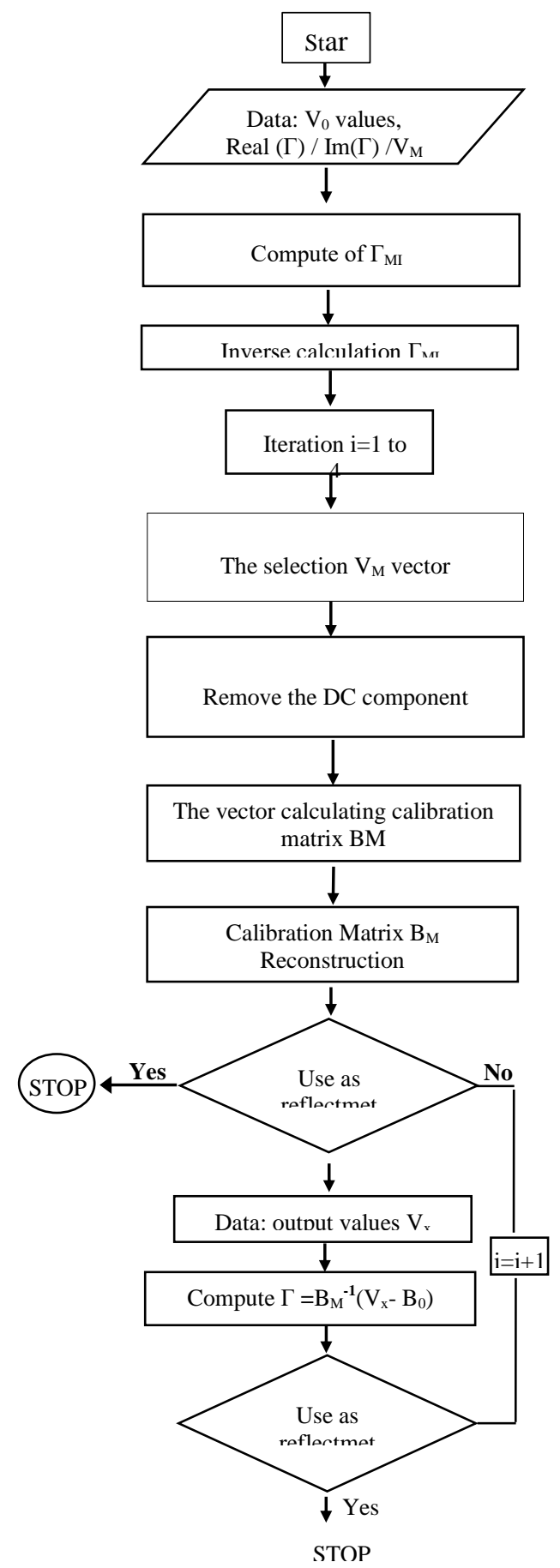


The S parameters of six-port calibrated can be regarded as being the same at the frequency difference $f_{2}-f_{1}$ if this difference is very small. Let us consider the cases where the incidents wave "a" and the reflected wave " $\mathbf{b}$ " are different in frequency as in the equations (3) and (4) above. The equivalent reflection coefficient becomes:

$\Gamma=\frac{b}{a} e^{j\left[2 \pi\left(f_{2}-f_{1}\right)-\left(\emptyset_{2}-\emptyset_{1}\right)\right]}$

The reflection coefficient $\Gamma$ becomes a time-dependent vector whose amplitude is invariant and the phase is around at a constant angular speed $2 \pi \Delta f$, where $\Delta f=f_{2}-f_{1}$

The voltage at a detector port of the six-port is a vector summation of portions of $\mathbf{a}$ and $\mathbf{b}$ presented at the port, the output voltage waveforms of the power detectors are:

$\mathrm{V}_{\text {out }, \mathrm{i}}=\frac{1}{2}\left(\left|\mathrm{a}_{\mathrm{i}}\right|^{2}+\left|\mathrm{b}_{\mathrm{i}}\right|^{2}\right)+\left|\mathrm{a}_{\mathrm{i}}\right| \cdot\left|\mathrm{b}_{\mathrm{i}}\right| \cdot \cos \left(2 \pi \Delta \mathrm{ft}+\Delta \emptyset_{\mathrm{i}}\right)$

Where $a_{i}$ and $b_{i}$ are waves corresponding to $\mathbf{a}$ and $\mathbf{b}$ at port $\mathrm{i}, i=3, \ldots, 6$

The four output voltage waveforms $\left(\mathrm{v}_{1}, \mathrm{v}_{2}, \mathrm{v}_{3}\right.$ and $\left.\mathrm{v}_{4}\right)$ of a six-port reflectometer are shown in Fig. 5:

We note that a period of the waveform corresponds to a whole circle of $\Gamma$ rotating in the complex plane. We select the samples at an equal amplitude space in the whole voltage swing in this channel; these samples will present a group of equally spaced terminations on a circle in the $\Gamma$ plane.

To ensure the communication of the user with the program, we have made use of a graphical interface.

The final circuit of six-port reflectometer is designed and simulated at Fig. 6 to validate results introduced in Fig. 5. The Graphical interface based at the above program, offers us the possibility to calculate the reflection coefficient of a device under test. The DUT is connected to the input of six-port reflectometer.

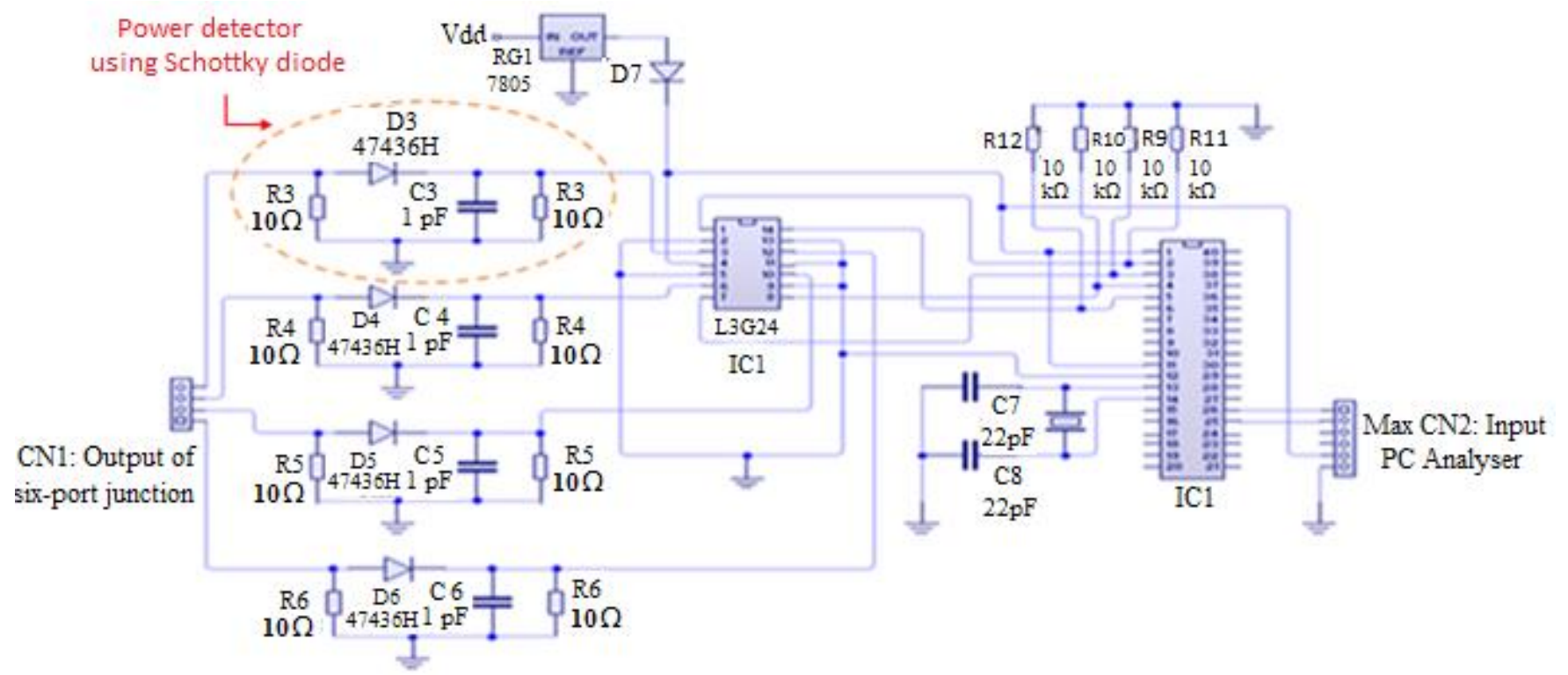

Fig. 6. Graphical Interface of Six-Port Recflectometer.

www.ijacsa.thesai.org

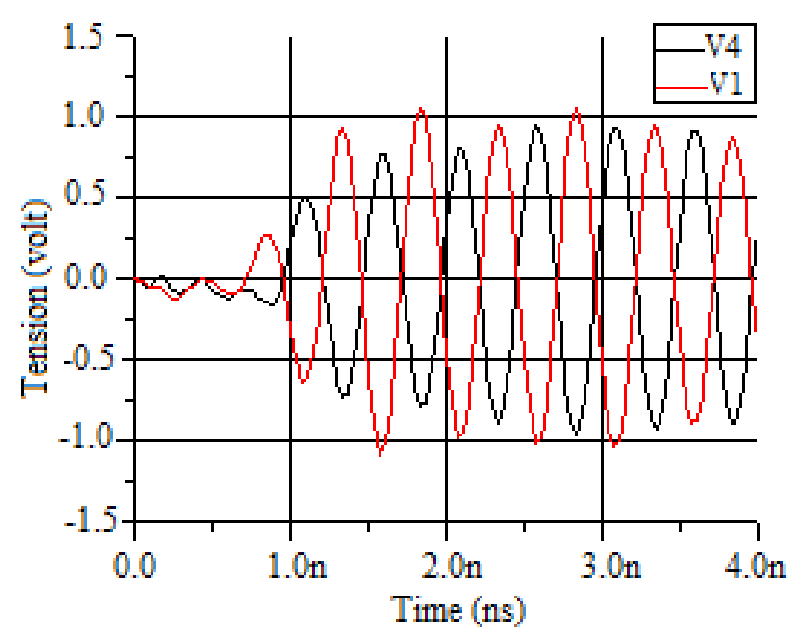

(a)

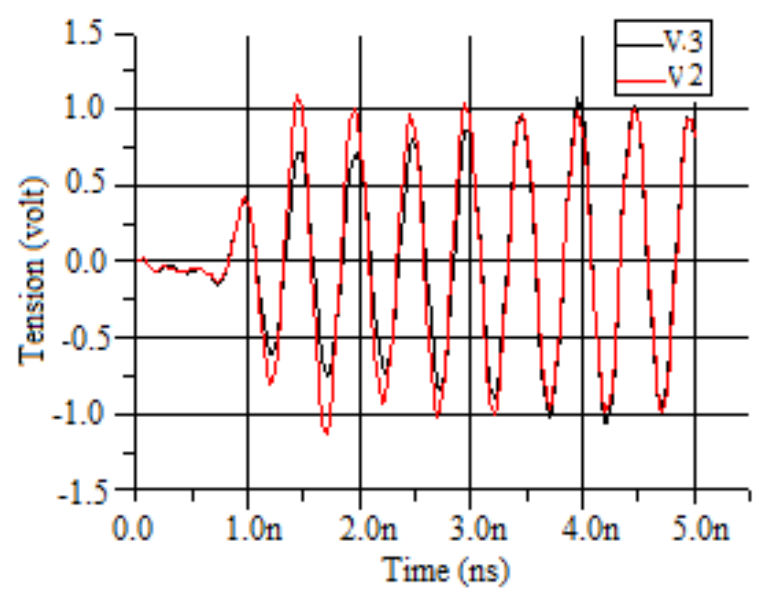

(b)

Fig. 5. (a): V1, V4 and (b): V2, V3 Output Wave forms of a Six-Port Reflectometer, Simulation Results. 


\section{B. Validation by Measuring Test Loads}

To validate calibration technique performance of miniaturized six-port junction, circuit is realized with screen printing technique; this process is used due to its ability to print a flexible substrate. AC voltage is the output of six-port junction and the input of four power detectors circuit to convert it to de voltage; we need to connect at the output of power detectors LM324N to increase the output voltage.

LM324N is a 14pin IC consisting of four independent operational amplifiers compensated in a single package. Signal at output of op-amps implement microcontroller mikroC PRO for PIC to validate calibration technique.

The final hybrid prototype and photograph experimental setup system shown in Fig. 7.

Results of reflection coefficients performed is comparing with the program above those found by experiment prototype. The load under test is composed of lumped elements in series (Inductance, Resistance and Capacity), by varying the amplitude of either the input signal, samples of $\Gamma^{\prime}$ s well distributed over the whole Smith chart can be obtained.

In order to test the validity of the six-port calibration, a calculation of relative and average errors are shown, results are presented in Table II.

Table above lists the calculation errors obtained for different samples. It can be seen that the relative error for the real parts of the reflection coefficients is about $6 \%$ except for very low reflection loads. In another hand it is noticed that the relative error for the imaginary parts of the reflection coefficients is about $4.8 \%$.

In most case, the difference of errors between the real and imaginary parts is in order of 0.01 . Note that the readings are taken from a real time continuous display of reflection coefficients. Analysis results are confirmed schematically by the calibration technique studied in Smith chart below.

Fig. 8 shows a maximum of agreement between experimental results, simulation and algorithm taking samples of plane calibration in terms of reflection coefficient. It's very clear for large impedances and inductive loads (positiveimaginary part). Note that the error increases inversely with the impedance, this is due to the relative error of the load impedance.

This error is higher for the low impedances than for high impedance of the load. But errors have several origins, particularly for millimeter frequencies, the achievement of a reflectometer generates imperfections that away from the perfect model.

As well as the adaptation errors, isolation and directivity of the source and the load. It will be impossible to get such perfect $50 \Omega$ terminated transmission lines or lossless, in addition to the accuracy of the model of the output voltages.



Fig. 7. Displaying Meter Results with Graphical Interface.

TABLE II. IMPEDANCE AND REFLECTION COEFFICIENT LOADS

\begin{tabular}{|c|c|c|c|c|c|c|c|c|c|}
\hline $\mathrm{R}(\mathrm{S} 11)$ & $\mathrm{I}(\mathrm{S} 11)$ & $\mathrm{R}(\mathrm{OHM})$ & Z(H OU F) & $\mathrm{R}$ & Q & DELTA (R) & DELTA(Q) & $\mathrm{DR}^{2}$ & $\mathrm{DQ}^{2}$ \\
\hline 0 & 0 & $\mathrm{CA}$ & $\mathrm{CA}$ & 0 & 0 & 0 & 0 & 0 & 0 \\
\hline 1 & 0 & $\mathrm{CO}$ & $\mathrm{CO}$ & 0,93 & 0,04 & 0,07 & $-0,04$ & 0,0049 & 0,0016 \\
\hline-1 & 0 & $\mathrm{CC}$ & $\mathrm{CC}$ & -1 & 0,07 & $-0,05$ & $-0,07$ & 0,0025 & 0,0049 \\
\hline 0,5 & 0,5 & 50 & $8 \mathrm{E}-09$ & 0,55 & 0,52 & $-0,05$ & $-0,02$ & 0,0025 & 0,0004 \\
\hline 0,4 & 0,7 & 20,588 & $6,6 \mathrm{E}-09$ & 0,48 & 0,72 & $-0,08$ & $-0,02$ & 0,0064 & 0,0004 \\
\hline 0,3 & 0,3 & 70,68 & 4,1E-09 & 0,35 & 0,31 & $-0,05$ & $-0,01$ & 0,0025 & 0,0001 \\
\hline 0 & 1 & 0 & 4E-09 & -0 & 0,98 & 0,022 & 0,02 & 0,0005 & 0,0004 \\
\hline$-0,471$ & 0,883 & 0 & 2,4E-09 & $-0,3$ & 0,98 & $-0,131$ & $-0,097$ & 0,0172 & 0,00941 \\
\hline \multicolumn{6}{|c|}{ Addition } & 6,841 & 10,339 & 0,1974 & 0,24743 \\
\hline \multicolumn{6}{|c|}{ Relative error } & 0,065 & 0,04811 & Relative error & 0,065 \\
\hline \multicolumn{6}{|c|}{ Average error } & 0,0202 & 0,02261 & Average error & 0,0202 \\
\hline
\end{tabular}




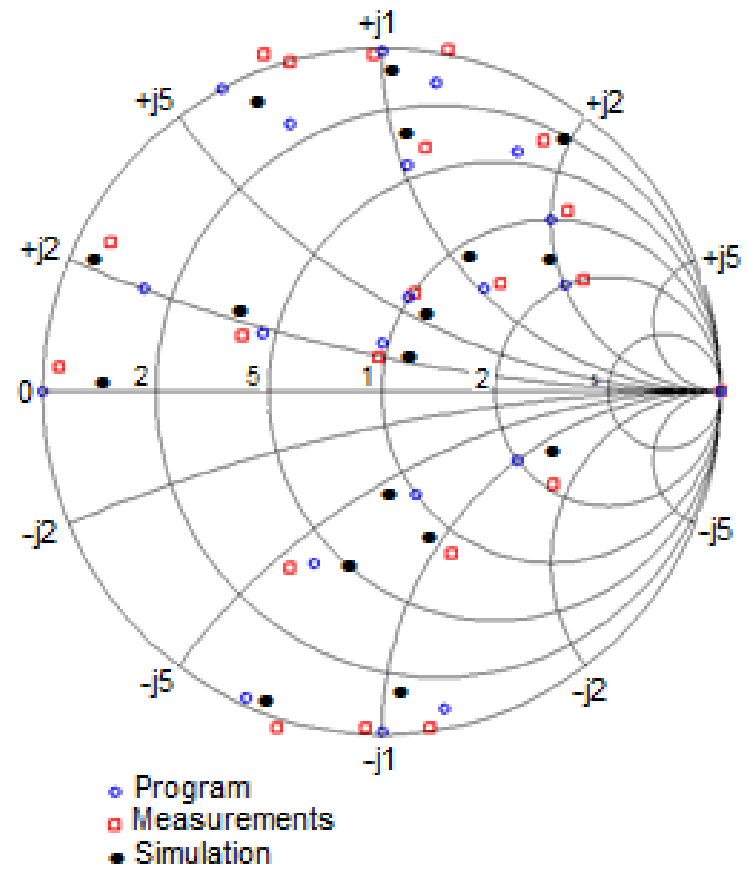

Fig. 8. Smith Chart of the Reflection Coefficients with Algorithm, Simulation and Experiment Prototype.

\section{CONCLUSION}

A novel explicit calibration for six-port reflectometer incorporating new four-port correlators has been proposed and shown. A linearization procedure and an AC detection technique are used to improve the measurement accuracy. This solution makes a good compromise between the number of calibration standards, the computational cost and the accuracy.

Regarding calibration considerations, a further improvement in the technique will be used to achieve measurements in the $1-10 \mathrm{GHz}$ frequency range. Therefore the proposed technique program is suitable for wireless communication system and can successfully replace the classical calibration methods.

\section{ACKNOWLEDGMENT}

The Authors acknowledge the support of Riyadh College of Technology and especially electronics Department.

\section{REFERENCES}

[1] K. Haddadi, Tuami Lasri, "Formulation for Complete and Accurate Calibration of Six-Port Reflectometer “, IEEE Trans, Microwave Theory Tech, vol. 60, no 3, pp. 574- 581, March 2012.

[2] Kamil Staszek, "Six-Port Calibration Utilizing Matched Load and Unknown Calibration Loads,“ IEEE Trans, Microwave Theory Tech, vol. 66, no 10, pp. 4617-4626, oct 2018.

[3] Abul Hasan, Mohamed Helaoui, "Formulation for Complete and Accurate Calibration of Six-Port Reflectometer,“ IEEE Trans, Microwave Theory Tech, vol. 60, no 12, pp. 574-581, 2012.

[4] Abdullah O. Aolopade, Mohamed helaoui, "High performance homodyne six-port receiver using memory polynomial calibration," 2014 IEEE 27 th Canadian conference on Electrical and Computer Engineering CCECE 2014.

[5] Kamil Staszek "Six-port Calibrating Utilizing Matched Load and Unknown Calibration Loads, “ IEEE Transactions on Micrwave Theory and Techniques vol 66, no 10, pp. 41-44, 2018.

[6] Traii Moubarek, Ali Gharsallah, "A Six-Port Reflectometer Calibration Using Wilkinson Power Divider," American Journal of Engineering and Applied Sciences, vol. 10, pp.38-44, Jun 2016.

[7] K. Haddadi, D. Glay, and T. Lasri, "Homodyne dual six-port network analyzer and associated calibration technique for millimetre wave measurements, "Int. Symp. Circuits Syst., Island of Kos, Greece, IEEE, pp. 1-4, May 2006.

[8] Traii Moubarek, Mourad Nedil, Ali Gharsallah, Tayeb A. Denidni, "A New wideband Six-port Junction using single layer Technology, "International Journal of Information Sciences and Computer Engineering, vol. 2, NO. 2, pp.14-48, Jun 2011.

[9] Fadhel M. Ghannouchi, Abbas Mohammadi, "The six-port Technique with Microwave and Wireless Applications, "Aretch House Microwave Library, 2009.

[10] S.Wafi, "Study of a system based on microwave junction six-port with associated calibration technique, “ Master Degree, El Manar University, Tunisia, 2011.

[11] C. Potter and A. Bullock, "Non-linearity correction of microwave diode detectors using a repeatable attenuation step," Microwave Journal, vol. 36, pp. 272, 274 and 277-279, May 1993.

[12] Kamil Staszek, Sarah Linz, Fabian Lurz, Sebastian Mann, and Robert Weeigel, Alexander Koelpin, "Improved calibration procedure for sixport based precise displacement measurements," 2016 IEEE Topical Conference on Wireless Sensors and Sensor Networks (WiSNet), 2016.

[13] Jigisha Das, Srimoyi Roy, Rijubrata Pal, Mrinal Kanti Mandal, "Rive points method of calibration for six-port receivers," $20183 \mathrm{rd}$ International Conference on Microwave and Photonics (ICMAP), 2018.

[14] K.Haddadi, C. Loyez, L.Clavier, D.Pomorski, S.Lallemand, "Six-port reflectometer in WR15 metallic waveguide for free-space sensing applications," 2018 IEEE Topical Conference on Wireless Sensors and Sensor Networks (WiSNet), pp. 80-83, March 2018.

[15] Vladimir Bilik, Six-port Measurement Technique : Principles, Impact, applications, Slovak University of Technology. 